\title{
THERMAL PROTECTIVE PERFORMANCE OF FIREFIGHTERS' CLOTHING UNDER LOW-INTENSITY RADIATION HEAT EXPOSURE
}

\author{
Hualing He ${ }^{1,2}$, Zhicai Yu, ${ }^{1,}$, Chunbo Zhang ${ }^{3}$, Minhua $\mathrm{Li}^{3}$ \\ 1 Hubei Key Laboratory of Biomass Fibers and Eco-Dyeing \& Finishing, College of Chemistry and Chemical Engineering, Wuhan Textile University, Wuhan \\ 430200, China \\ 2 Key Laboratory of Clean Dyeing and Finishing Technology of Zhejiang Province, Shaoxing 312000, China \\ 3 College of Advanced Textile, Wuhan Textile University, Wuhan 430200, China \\ ${ }^{*}$ Corresponding author. E-mail: yuzhicaicai@163.com
}

\begin{abstract}
:
The stored energy provided by the fabric assemblies will greatly influence the thermal protection performance (TPP) of firefighters' protective clothing under low-intensity radiation heat exposure. In this study, two test methods, namely radiant protective performance (RPP) and stored energy test (SET), were used to investigate the TPP of the fabric assemblies. The results indicated that $T_{S E T}$ value was lower than $T_{R P P}$ value because of the release of the stored energy in the fabric assemblies after heat exposure. Increasing the fabric layer numbers, air gap between the fabric assemblies would increase the time of $T_{R P P}$ and $T_{S E T}$, indicating that the thermal stored energy weakened the TPP of the firefighters' protective clothing. Moreover, the $T_{R P P}$ and $T_{S E T}$ of the fabric system would be increased when the moisture barrier was cut in the fabric combination system. These findings suggested that stored energy should be considered in analyzing the TPP of fabric assemblies..
\end{abstract}

\section{Keywords:}

Firefighters' protective clothing, thermal protection performance, stored thermal energy, low radiant heat exposures

\section{Introduction}

The thermal protection performance (TPP) of firefighters' protective clothing against radiation heat is a critical property for multilayer fabric system, especially during fire operation and rescue. There are various test methods available for measuring the TPP of fabric assemblies used by wildland firefighters. Among these methods, the bench-scale test was the simplest method to understand the TPP of firefighters' clothing under heat exposures. Many researchers have extensively investigated the TPP levels of the multilayer fabric combinations by using a radiant protective performance (RPP) tester under different radiation heat exposures. Shalev and Barker investigated the relationship between physical properties and TPP of numerous heat-resistant fabrics [1]. Lee and Barker investigated the effects of moisture content in fabrics on the TPP of firefighters' protective clothing when exposing to thermal assaults lower than flashover conditions [2]. The results indicated that moisture in the firefighters' clothing displays negative effect in blocking the heat transfer in the multilayer fabric system when the added moisture is in a comparatively low level. Sun et al. evaluated the RPP of a series of single-layer fabrics [3]. Their study indicated that the RPP was affected by the structure, weight, thickness, and materials of the fabric assemblies. Lawson et al. examined the effects of the amount and location of moisture on heat transfer in fabric assemblies systems, which typically belong to wildland firefighters' protective clothing [4]. They concluded that moisture can have negative or positive affect on the TPP, according to the moisture content of the fabric combination system. A study by Wang et al. evaluated the effects of air-gap size and position on TPP of protective clothing when exposed to an $84 \mathrm{~kW} / \mathrm{m}^{2}$ heat source [5]. Furthermore, Li et al. investigated the thermal protection of flame-retardant fabrics used as firefighters' protective clothing under three types of relative humidity $(\mathrm{RH})$ in microclimates when exposed to flash fires of $84 \mathrm{~kW} / \mathrm{m}^{2}$ [6]. These results implied that the $\mathrm{RH}$ in microclimates displayed positive effect on the TPP of flame-resistant fabrics exposed to flash fires. In our previous study, the effects of moisture and air gap on the TPP of fabric assemblies used by wildland firefighters have been investigated [7].

Despite the conventional TPP/RPP test helps in understanding the mechanisms and relevant factors associated with TPP provided by fabrics, most studies consider only the effect of heat transfer on skin burns during thermal exposure and ignore skin burn injuries caused by the heat released from the protective clothing after heat exposure [8-11]. To comprehensively evaluate the TPP of protective clothing, the effects of stored energy on skin burns should be given full consideration. The stored energy test (SET) method could predict the heat storage released on the skin burns during the cooling phase after the end of heat exposure, which could provide better understanding of TPP of the fabrics [12-14].

Fire types decided the fire environments. Many studies have reported the TPP of fabric or clothing exposed to emergency fire environments [15-17]. Exposure to low-level thermal radiation ranging from 5 to $20 \mathrm{~kW} / \mathrm{m}^{2}$ is one of the most common thermal 
hazards that can cause skin burn injuries [18]. Generally, few minutes of heat exposure do not seriously damage the appearance of the fabric due to the low heat flow intensity. However, the discharge of stored thermal energy stored within the fabrics after the heat exposure often leads to skin burns in firefighters. Therefore, the hazard of stored thermal energy must be considered for the firefighters' protective clothing.

In this study, two test methods, namely RPP and SET, were used to investigate the TPP of the fabric assemblies including single layer, double layer, and multilayer fabric combinations. To better simulate the heat transfer property of skin, traditional copper sensor was replaced by the self-made skin simulant sensor that is made from inorganic material with similar thermal capacity corresponding to the skin. Moreover, we also developed the virtual temperature tester based on Labview 2010 software to collect sensor data and control it in real time. The effect of different fabric combinations, air gap, reflective trim, and moisture barrier integrity on the TPP of firefighters' protective clothing was investigated under low levels of radiant heat exposure. New knowledge gained from this study may provide valuable insight for predicting human skin burns and the TPP of firefighters' protective clothing against radiant heat exposure.

\section{Experimental}

\subsection{Materials}

The basic specifications of selected fabric samples are listed in Table 1. These deliberately selected fabric specimens are commercially available, and high-performance fabrics were used as firefighters' protective clothing. We combined the fabric assemblies as single-layer fabric (used for coveralls), doublelayer systems, and multilayer constructions and used them for firefighters' protective clothing. The details of the fabric system construction and physical properties are shown in Table 2. Before testing, specimens were preconditioned in a standard atmosphere $\left(20 \pm 2^{\circ} \mathrm{C}\right.$ and $\left.65 \pm 5 \% \mathrm{RH}\right)$ for at least $24 \mathrm{~h}$.

\subsection{Test apparatus}

Figure 1 shows the schematic of bench-top test apparatus. The skin simulant sensor was used in this study instead of the original copper sensor in the equipment. The skin simulant sensor is constructed of an inorganic material with similar thermal capacity corresponding to the skin. Thus, its heat transfer method was close to the human skin, making the test data reliable. The heat sources include two Meker burners and a bank of heated quartz tubes. In this study, only the heated quartz tubes were used to produce a nominal pure radiant heat flux. Heat flux was measured by the skin simulant sensor behind the test sample. We also developed the virtual temperature tester based on Labview 2010 software to collect sensor data and control it in real time. In this experiment, we evaluated the TPP based on the Henriques burn integral equation instead of Stoll curve for skin burn which is suitable only for the test method using copper sensor. The air gap between the fabric combination and sensor was produced by holding frames.

\subsection{Experimental protocol}

Based on NFPA 1977 and ASTM F 2731, we evaluated the radiation protection performance and thermal storage performance of fire-resistant fabrics by RPP and SET methods

Table 1. Parameters of fabric samples

\begin{tabular}{|c|c|c|c|c|}
\hline Fabric code & Fiber content & Weigh (g/m2) & Thickness (mm) & Weave structure \\
\hline A & $\begin{array}{c}98 \% \text { Nomex/2\% antistatic } \\
\text { fiber }\end{array}$ & 203.18 & 0.34 & Twill \\
\hline B & $\begin{array}{c}80 \% \text { Nomex/20\% flame- } \\
\text { retardant viscose }\end{array}$ & 222.33 & 0.34 & Twill \\
\hline C & $100 \%$ Nomex & 115.32 & 0.50 & Water thorn felt with PTFE \\
\hline D & $100 \%$ Nomex & 204.65 & 0.93 & $\begin{array}{c}\text { Needling nonwoven with } \\
\text { Nomex/antistatic woven face }\end{array}$ \\
\hline
\end{tabular}

Table 2. Structural and physical properties of fabric assemblies

\begin{tabular}{|c|c|c|c|c|}
\hline Assemblies code & Fabric assembly description & Thickness $(\mathbf{m m})$ & Weight $\left(\mathbf{g} / \mathbf{m}^{2}\right)$ & Air permeability $\left(\mathbf{I} / \mathbf{m}^{2} / \mathbf{s}\right)$ \\
\hline S1 & Fabric A & 0.34 & 203.18 & 95.2 \\
\hline S2 & Fabric B & 0.34 & 222.33 & 178.0 \\
\hline S3 & Fabric A + Fabric C & 0.84 & 312.20 & 0 \\
\hline S4 & Fabric B + Fabric C & 0.84 & 331.35 & 0 \\
\hline S5 & Fabric A + Fabric C + Fabric D & 1.77 & 517.03 & 0 \\
\hline S6 & Fabric B + Fabric C + Fabric D & 1.77 & 536.0 & 0 \\
\hline
\end{tabular}




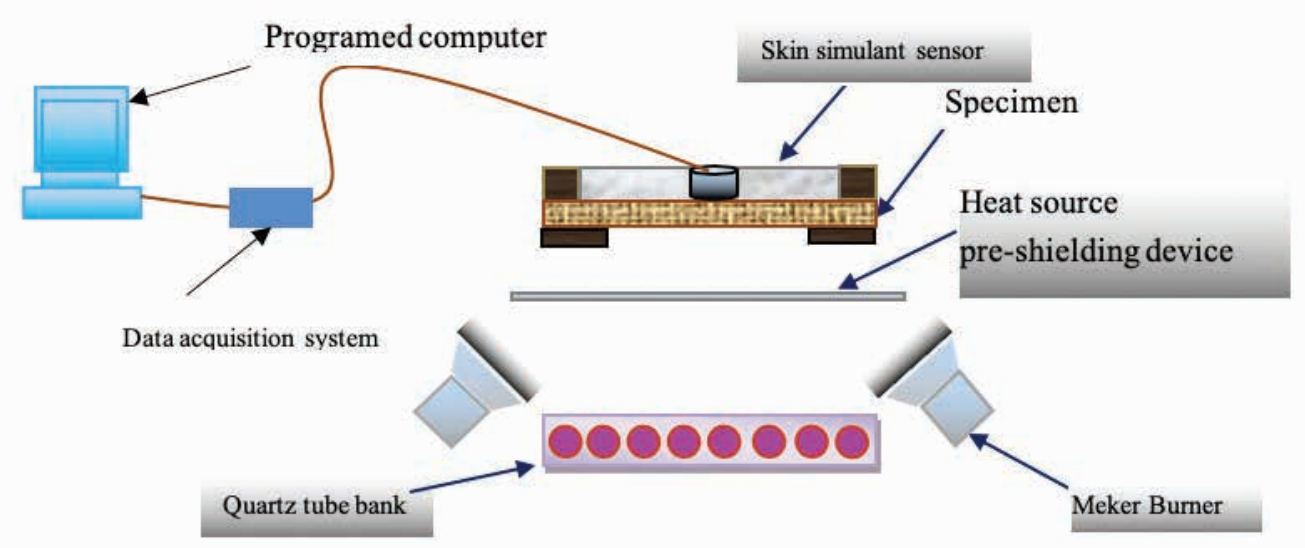

Figure 1. Schematic of modified bench top test apparatus [7].

(minimum heat exposure time method). The specific test steps are as follows:

(1) Starting the TPP tester and calibrating the radiation heat level for a certain value (provided by nine infrared quartz lamps).

(3) Placing the pretreated fabric sample horizontally on a specific sample holder and starting the program (the standard TPP tester was reprogrammed).

(5) Exposing the fabric sample to the preset heat source and starting data acquisition simultaneously.

(8) Exposure and data acquisition were stopped after the preselected exposure time.

(11) Using the collected data, we calculated the skin burns. If a second-degree burn was not predicted, we repeated the test with a new sample and given a prolonged exposure time. We continued retesting until a second-degree burn was predicted. We recorded the second-degree burn time as $T_{\mathrm{RPP}}$.

(14) If the effect of thermal storage on the TPP was considered, then the following procedure was implemented as follows:

(a) The exposure was stopped and data acquisition was continued until a predetermined time (including thermal exposure time and cooling period).

(c) If a second-degree burn was not predicted during the cooling period, we would increase the exposure time and repeat the test by using a new sample. We continued retesting until the seconddegree burn time was predicted. The exposure time used in this last test became the minimum value of exposure time or $T_{\mathrm{SET}}$. We recorded the second-degree burn time as $T_{\text {RPP }}$.

(g) If a second-degree burn time was predicted during cooling period, we would reduce the exposure time and repeat the test by using a new sample. We continued retesting until no second-degree burn was predicted. The last exposure time that generated a second-degree burn prediction became the minimum value of exposure time or $T_{\mathrm{SET}}$.

(n) If no secondary burn was observed in the cooling phase after the end of the heat exposure, we would increase the heat exposure time by using a new sample to repeat the experiment until the secondary burn occurring exactly in the fabric cooling stage. The thermal exposure time of the experiment was noted as the minimum heat exposure time and recorded as $T_{\text {SET }}$.

\section{Results and discussion}

\subsection{Effects of radiant heat exposure level on TPP}

$T_{\text {RPP }}$ and $T_{\text {SET }}$ of the different fabric systems exposed to three levels of heat exposure were presented in Table 3. The results showed that $T_{\text {RPP }}$ and $T_{\text {SET }}$ of the fabric combination systems are significantly different under different heat radiation intensities. It was further found that $T_{\mathrm{SET}}$ value is lower than the $T_{\mathrm{RPP}}$ value tested by using the traditional method because the heat accumulation test considered only the heat release on the skin burns after heat exposure. From Table 3, it was found that increasing the combination of fabric numbers would significantly increase the $T_{\mathrm{RPP}}$ and $T_{\mathrm{SET}}$. The results indicated that increasing the fabric combination numbers would increase the thickness and weight of the firefighters' protective clothing which decreased the thermal conductive property. Thus, the high thickness and weight of the fabric system indicated corresponding increase in $T_{\text {RPP }}$ and $T_{\text {SET }}$ values. This phenomenon was consistent with the study by Torvi and 
Hadjisophocleous [19]. Song et al. also found that increasing thickness of the test fabric could increase the secondary burn time. However, it is a nonlinear correlation that exists between the two factors [20]. Static air has lower thermal conductivity compared with fibers. A large amount of static air will be exited in multilayer fabric system when increasing the fabric thickness. The presence of static air in fabric combination system can prevent the heat transfer to the skin simulant sensor due to low air thermal conductivity. Thus, the great number of layers of the fabric combinations under the same radiant heat intensity indicated that $T_{\mathrm{SET}}$ is lower than $T_{\mathrm{RPP}}$. This was mainly due to increase in the layer numbers that could increase the stored energy in the interior of fabric combination system. When the heat exposure was over, the stored energy in the protective clothing would continuously release energy and harm the skin. Therefore, the value difference between $T_{\mathrm{RPP}}$ and $T_{\mathrm{SET}}$ will become larger with the increase of fabric thickness.

Figure 2 shows the heat flow curves of the six combinations of fabrics under different radiant heat intensities. The graph shows that increased radiant heat intensity during thermal exposure means increased heat transfer to the skin sensor through the fabric system, thereby resulting in decreased $T_{\text {RPP }}$ and $T_{\text {SET }}$. Furthermore, the graph shows that the values of $T_{\text {RPP }}$ and $T_{\mathrm{SET}}$ of the single-layer fabric are short, followed by the double-layer fabric, whereas the values of $T_{\mathrm{RPP}}$ and $T_{\mathrm{SET}}$ of the three-layer fabric combination are the longest.

\subsection{Effect of air gap on TPP}

Usually the bench-top scale test of TPP does not consider the impact of air gap between the fabric and skin. Some standards set the air gap between the sensor and fabric as $6.4 \mathrm{~mm}$. In previous studies, it was concluded that the air layer thickness significantly affects the heat transfer performance of the fabric systems [21]. If the thickness is too high, natural convection may occur in the air gap and the TPP of the fabric will be greatly reduced. A large number of scholars have explored the effect of air layer on the TPP under the convection/radiation or pure radiation exposure [22]. However, only few studies are available on the effects of air gap on thermally stored performance evaluation exposed to low-level radiant heat sources [23]. In this experiment, we investigated $T_{\mathrm{RPP}}, T_{\mathrm{SET}}$, and thermal storage indices (SEI) [described by Eq. (1)] in the presence of a singlelayer, double-layer, and multilayer fabric system in a $6.4 \mathrm{~mm}$ air gap under $16.8 \mathrm{~kW} / \mathrm{m}^{2}$ radiant heat exposure. The results are shown in Table 4. SEI was calculated by using Eq. (1).

$\mathrm{SEI}=\left(T_{\mathrm{RPP}}-T_{\mathrm{SET}}\right) / T_{\mathrm{SET}} \cdot=$

Table 4 shows that the presence of air gap between the fabric system and the skin simulant sensor significantly improved the TPP of the fabric system. Thus, the second-degree burn time of both $T_{\mathrm{SET}}$ and $T_{\mathrm{RPP}}$ was significantly increased. On the one hand, due to the decrease of the radiation angle of the air layer, the radiation heat transfer was weakened. On the other hand, the thermal conductivity of static air was only $0.02 \mathrm{~W} /(\mathrm{m} \cdot \mathrm{K})$

Table 3. TPP of fabric combination systems

\begin{tabular}{|c|c|c|c|c|c|c|c|c|}
\hline $\begin{array}{c}\text { Assemblies } \\
\text { code }\end{array}$ & $\begin{array}{c}\text { Thickness } \\
(\mathbf{m m})\end{array}$ & $\begin{array}{c}\text { Weight }(\mathrm{g} / \\
\left.\mathrm{m}^{2}\right)\end{array}$ & \multicolumn{3}{|c|}{$T_{\text {RPP }}(\mathbf{s})$} & \multicolumn{3}{|c|}{$T_{\text {SET }}(\mathbf{s})$} \\
\hline & & & $\begin{array}{c}16.80 \mathrm{~kW} / \\
\mathrm{m}^{2}\end{array}$ & $\begin{array}{c}11.44 \mathrm{~kW} / \\
\mathrm{m}^{2}\end{array}$ & $\begin{array}{c}7.26 \mathrm{~kW} / \\
\mathrm{m}^{2}\end{array}$ & $\begin{array}{c}16.80 \mathrm{~kW} / \\
\mathrm{m}^{2}\end{array}$ & $\begin{array}{c}11.44 \mathrm{~kW} / \\
\mathrm{m}^{2}\end{array}$ & $\begin{array}{c}7.26 \mathrm{~kW} / \\
\mathrm{m}^{2}\end{array}$ \\
\hline S1 & 0.34 & 203.18 & 14.57 & 26.21 & 44.53 & 14 & 25 & 41 \\
\hline S2 & 0.34 & 222.33 & 10.10 & 18.99 & 33.6 & 10 & 16 & 28 \\
\hline S3 & 0.84 & 312.20 & 16.48 & 28.55 & 47.17 & 11 & 22 & 37 \\
\hline S4 & 0.84 & 331.35 & 22.74 & 38.74 & 60.52 & 19 & 32 & 48 \\
\hline S5 & 1.77 & 517.03 & 42.46 & 68.44 & 104.2 & 32 & 56 & 89 \\
\hline S6 & 1.77 & 536.0 & 31.57 & 55.57 & 97.73 & 20 & 38 & 88 \\
\hline
\end{tabular}

Table 4. Effects of air gap on TPP

\begin{tabular}{|c|c|c|c|c|c|c|}
\hline \multirow{2}{*}{$\begin{array}{c}\text { Assemblies } \\
\text { Code }\end{array}$} & \multicolumn{3}{|c|}{ No air gap } & \multicolumn{3}{|c|}{ With air gap } \\
\hline & $T_{\mathrm{RPP}}(\mathrm{s})$ & $T_{\mathrm{SET}}(\mathrm{s})$ & SEI & $T_{\mathrm{RPP}}(\mathrm{s})$ & $T_{\mathrm{SET}}(\mathrm{s})$ & SEI \\
\hline S1 & 14.57 & 14 & 0.04 & 22.31 & 18 & 0.24 \\
\hline $\mathrm{S} 2$ & 10.1 & 10 & 0.01 & 19.76 & 15 & 0.32 \\
\hline S3 & 22.74 & 19 & 0.20 & 37.58 & 30 & 0.25 \\
\hline S4 & 16.48 & 11 & 0.50 & 29.65 & 19 & 0.56 \\
\hline S5 & 42.46 & 32 & 0.33 & 74.36 & 46 & 0.62 \\
\hline S6 & 31.57 & 20 & 0.58 & 55.21 & 32 & 0.73 \\
\hline
\end{tabular}




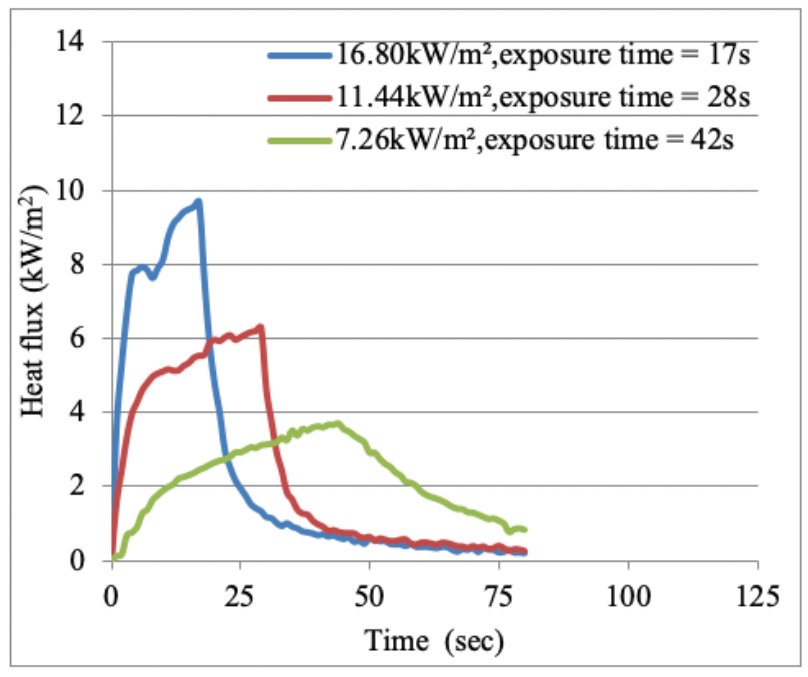

(a) $\mathrm{S} 1$

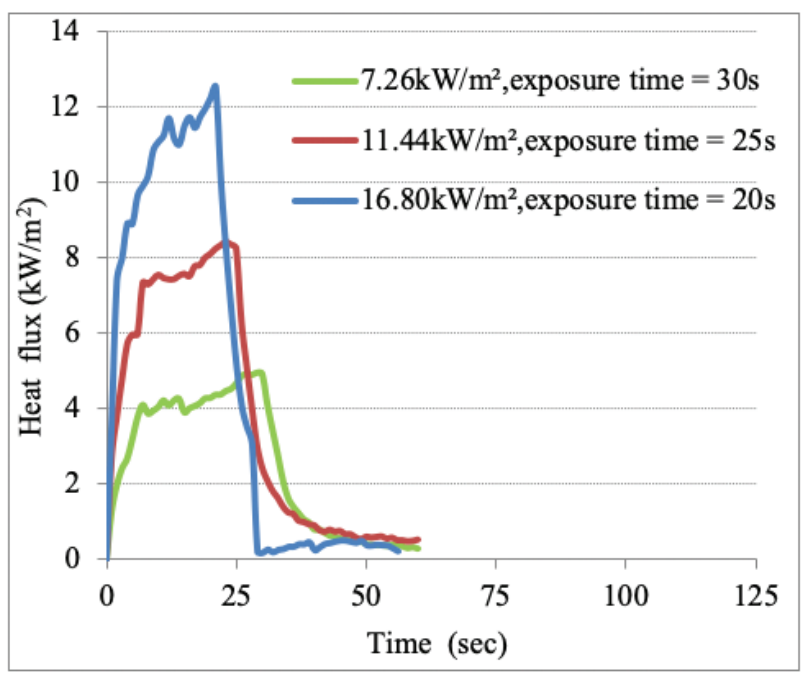

(b) S2

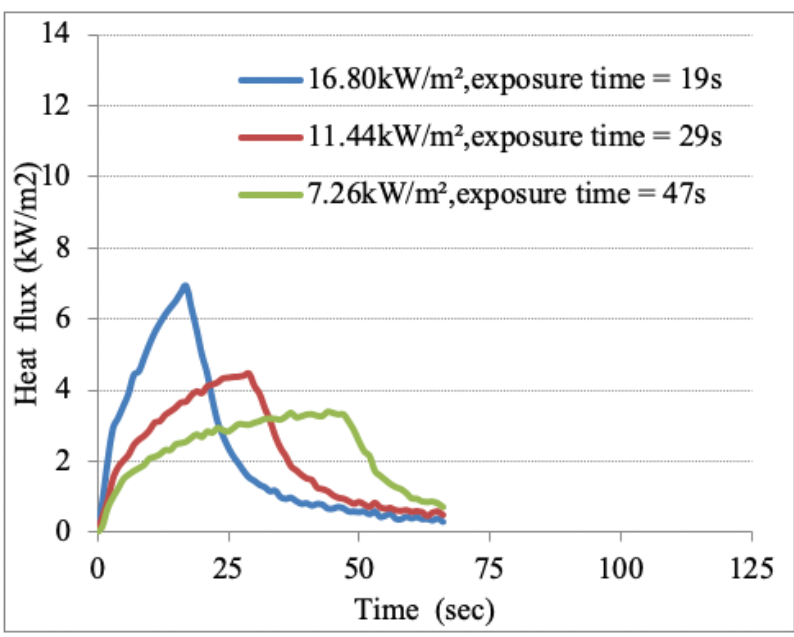

(c) $\mathrm{S} 3$

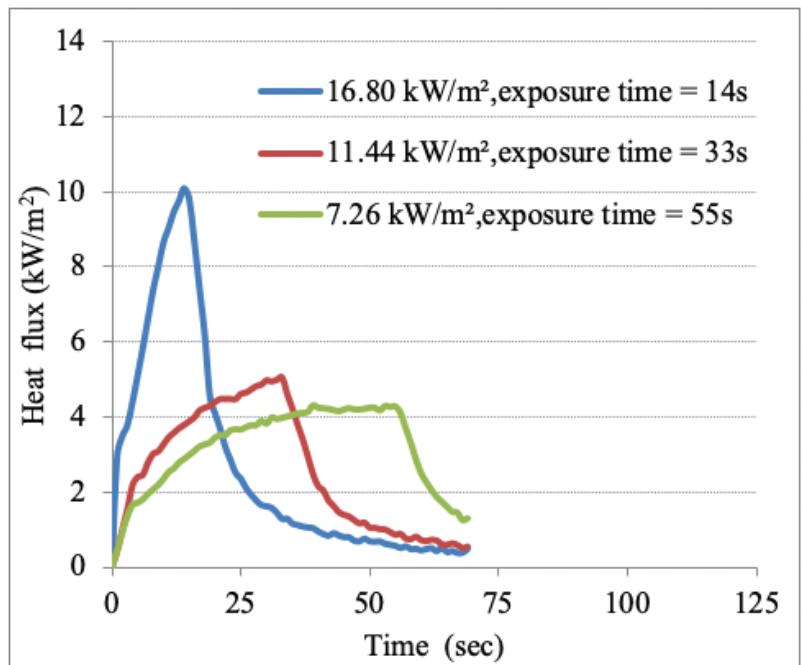

(d) S4

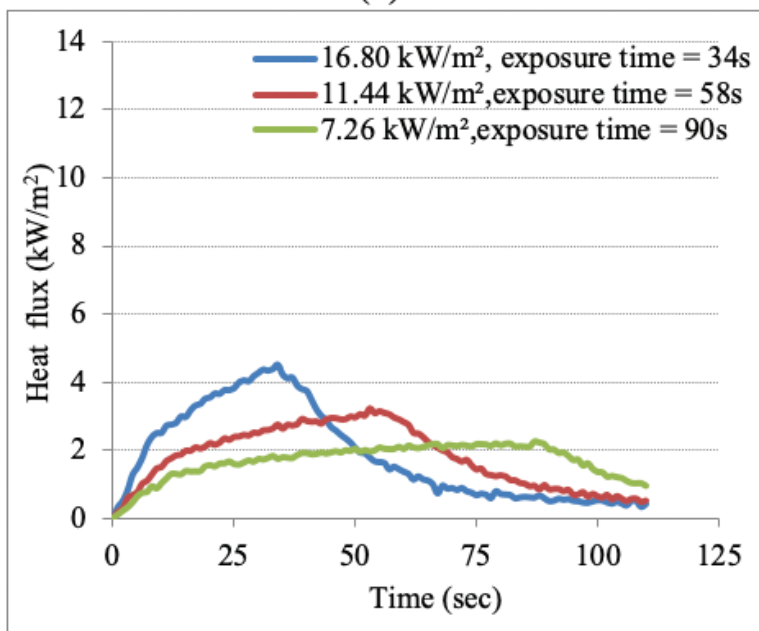

(e) S5

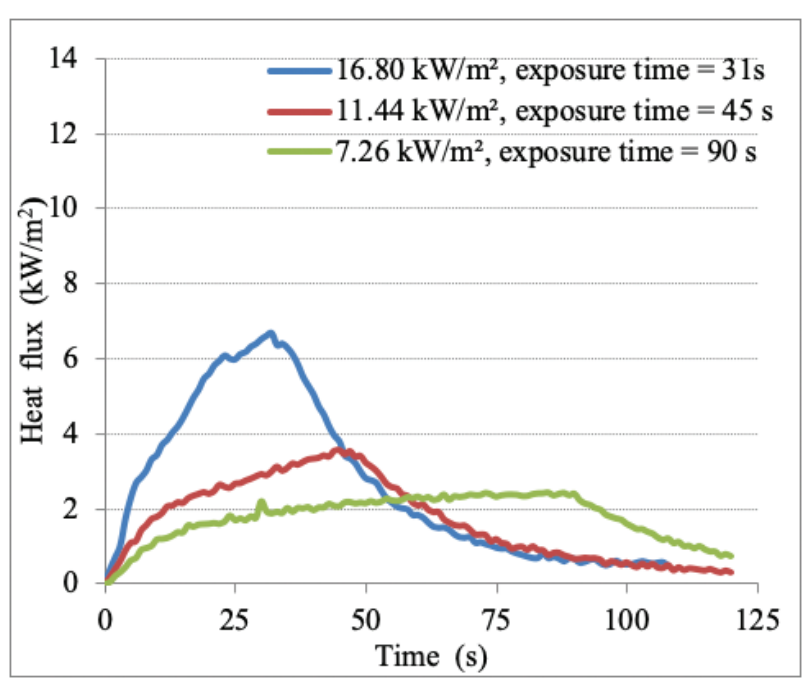

(f) S6

Figure 2. Heat flux profiles of fabric systems exposed to different levels of radiant heat.

which is lower than fiber. The heat transfer between the fabric combination system and the skin simulant sensor consists of heat radiation and heat conduction/heat convection. Combined with the literature [24], it can be considered that no natural 
convection occurred in the $6.4 \mathrm{~mm}$ static air layer in this study. Therefore, the air gap with a thickness of $6.4 \mathrm{~mm}$ between the fabric system and skin simulant sensor weakened the heat transfer. Generally, the thickness of fabric system will become large with the increase of layer numbers. Thus, increasing the number of layers of the fabric system means an increased effect of the heat storage release on the skin burns during the cooling period and the reduced effect of heat transfer in the heat exposure phase on human skin burns. Moreover, the addition of the air layer also increased the thermal storage index, indicating that the air layer accumulates a portion of the heat while acting as a heat-insulating medium, and that the accumulation of heat contributes to skin burn injuries.

Figure 3 shows the heat flow curves for six different fabric combinations (single, double, or triple layer) under exposure of $16.8 \mathrm{~kW} / \mathrm{m}^{2}$ radiant heat. It can be seen that with an air gap, the heat flux of the skin simulant sensor significantly reduced due to the presence of the static air layer that hindered the transfer of heat, thus prolonging second-degree burn times.

\subsection{Effects of reflective trim on TPP}

The reflective trim helps to improve clothing visibility because it can reflect light as a sign with the fabric sewn on the coat. To study the effect of the reflective tape on the TPP of the fabric synthesis, we exposed the fabric combinations S1, S4, and S5 to the $10.96 \mathrm{~kW} / \mathrm{m}^{2}$ radiant heat exposure.

The effect of reflective trim on the second-degree burn time is shown in Figure 4. The result indicated that the values of $T_{\text {RPP }}$ and $T_{\text {SET }}$ of fabric combinations increased after adding the reflective trim. The $T_{\mathrm{RPP}}$ values of $\mathrm{S} 1, \mathrm{~S} 4$, and $\mathrm{S} 5$ increased from $32.65,39.82$, and $71.21 \mathrm{~s}$ to $74.96,70.59$, and $86.48 \mathrm{~s}$, respectively. At the same time, $T_{\mathrm{SET}}$ values of $\mathrm{S} 1$, S4, and S5 increased from 28,33 , and 48 s to 54,48 , and $58 \mathrm{~s}$, respectively. These findings indicated that reflective trim displayed an obviously positive role on secondary burn time. However, Barker et al. found that the reflective tape reduced the thermal protection properties of the fabric system [25]. This result was contrary to the conclusion that the addition of the reflective trim in this study improves the TPP of the fabric system. It was mainly due to the different fabric properties of the reflective trim used in this study.

The effect of the reflective trim on the heat flow curve of S1 fabric is shown in Figure 5. The results show that the heat flux of the skin simulant sensor was obviously reduced after adding the reflective trim. After heat exposure for $35 \mathrm{~s}$, the heat flux of the skin simulant sensor behind the $\mathrm{S} 1$ fabric without reflective trim was $5.59 \mathrm{~kW} / \mathrm{m}^{2}$ and with reflective trim was $2.53 \mathrm{~kW} /$ $\mathrm{m}^{2}$. Thus, the addition of the reflective band significantly impeded the heat transfer and improved the TPP of the fabric combinations.

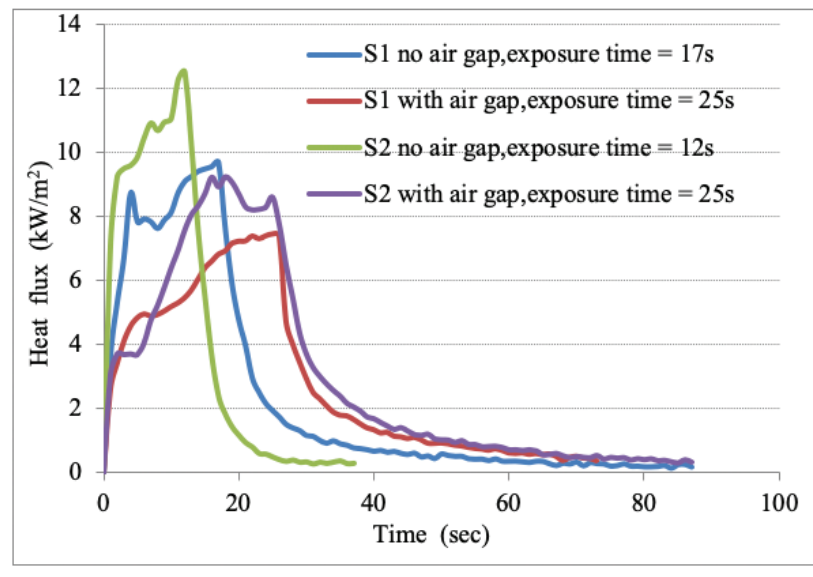

(a) S1 and S2

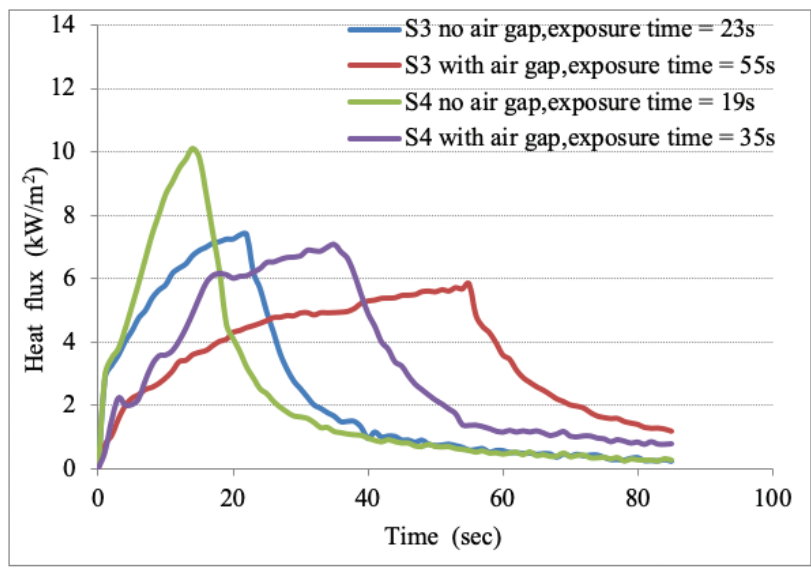

(b) S3 and S4

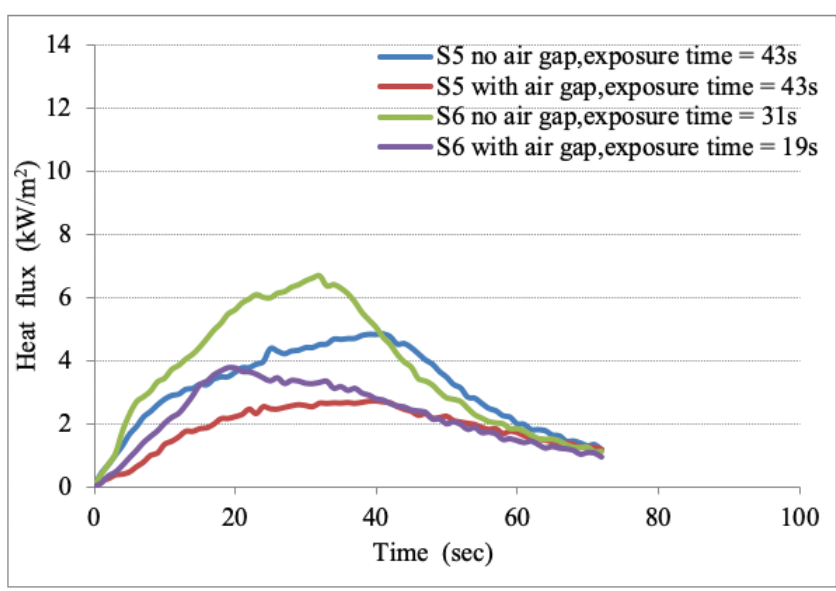

(c) S5 and S6

Figure 3. Heat flux profiles of fabric systems exposed to radiant heat with and without air spacer.

\subsection{Effect of moisture barrier integrity on TPP}

Generally, the moisture barrier layer in the fabric combinations could greatly reduce the breathability of the fabric system. In this study, some small pores were made by a knife to increase the permeability of the moisture barrier layer. In this study, the effect of integrity of fabric combinations on the TPP was investigated. The values of $T_{\text {RPP }}$ and $T_{\text {SET }}$ of fabric combinations 
Table 5. Effect of moisture barrier integrity on $T_{\mathrm{RPP}}$ and $T_{\mathrm{SET}}$

\begin{tabular}{|c|c|c|c|c|}
\hline Assemblies code & \multicolumn{2}{|c|}{ With integral moisture barrier } & \multicolumn{2}{c|}{ With breached moisture barrier } \\
\hline & $\boldsymbol{T}_{\mathrm{RPP}}(\mathbf{s})$ & $\boldsymbol{T}_{\mathrm{SET}}(\mathbf{s})$ & $\boldsymbol{T}_{\mathrm{RPP}}(\mathbf{s})$ & $\boldsymbol{T}_{\mathrm{SET}}(\mathbf{s})$ \\
\hline S4 & 37.54 & 32 & 44.18 & 33 \\
\hline $\mathrm{S} 5$ & 71.37 & 58 & 73.86 & 59 \\
\hline
\end{tabular}

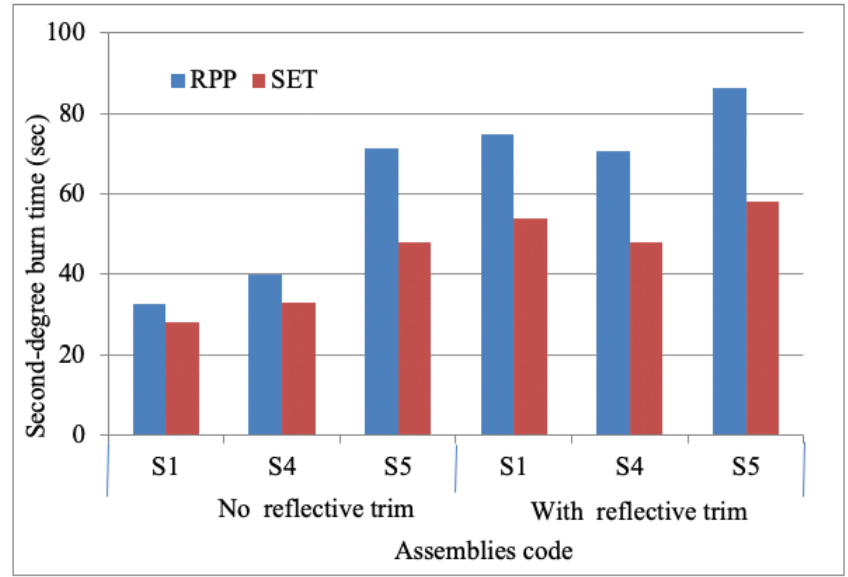

Figure 4. Effect of reflective trim on time required to generate seconddegree skin burn.

S4 and S5 are shown in Table 5 under exposure of $11.52 \mathrm{~kW} /$ $\mathrm{m}^{2}$.

From Table 5, it is surprisingly found that the values of $T_{\mathrm{RPP}}$ and $T_{\text {SET }}$ of the fabric system increased after moisture barrier was cut to have small pores. The results indicated that the values of $T_{\mathrm{RPP}}$ and $T_{\mathrm{SET}}$ of the double-layer fabric combinations are higher than that of three-layer fabric combinations. The reason for this phenomenon may be due to small pores on the moisture barrier which could retain a great amount of resting air and prevent the heat energy transfer. For the three-layer fabric combination, the effect of small pores on the heat transfer was weakened by the addition of the thermal layer. The heat flux curves of S4 and S5 fabric combinations are shown in Figure 6.

\section{Conclusions}

Firefighters' protective clothing is mainly used to reduce heat transfer to the skin under low-intensity radiation heat exposure, and its protective performance level depends on many factors. In this study, the effect of different fabric combinations, air gap, and moisture barrier integrity on the RPP and SET of fabric assemblies was investigated. The results indicated that the stored energy provided by the fabric assemblies will greatly influence the TPP of firefighters' protective clothing under lowintensity radiation heat exposure. For all the test samples, the time of $T_{\mathrm{SET}}$ was lower than the $\mathrm{T}_{\mathrm{RPP}}$. With the increase of fabric layer numbers in fabric assemblies, the difference between $T_{\text {SET }}$ and $T_{\text {RPP }}$ would become big. Moreover, the presence of air gap in the fabric combination system would increase the time of $T_{\mathrm{SET}}$ and $T_{\mathrm{RPP}}$, which was due to the heat-insulating property of static air. Finally, the $T_{\text {RPP }}$ and $T_{\text {SET }}$ of the fabric system

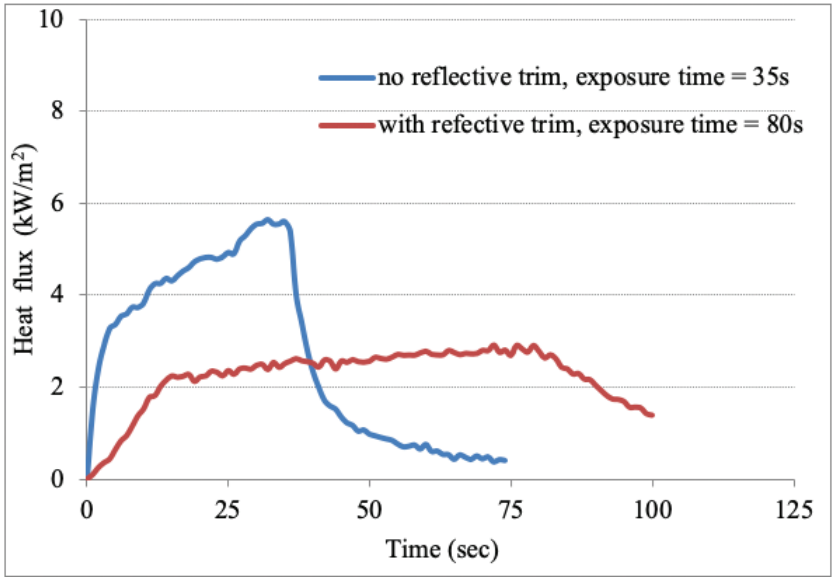

Figure 5. Heat flux profiles of S1 systems with and without reflective trim.

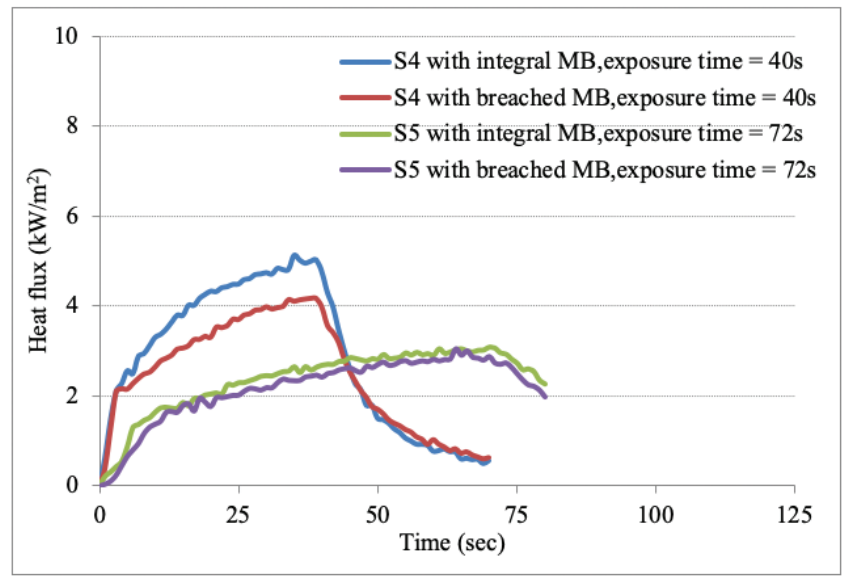

Figure 6. Effect of moisture barrier integrity on heat flux profiles.

would be increased when the moisture barrier was cut. In other words, TPP of the fabric combination system was improved. The earlier results hope to provide helpful guidance to the designer of firefighter protective clothing.

\section{Acknowledgement}

This research was supported from the Pening Project of Key Laboratory of Clean Dyeing and Finishing Technology of Zhejiang Province (1809, QJRZ1904), and undergraduate innovation and entrepreneurship training program from Hubei Province (S201910495027; S201910495070). 


\section{References}

[1] Shalev, I., Barker, R. L. (1983). Analysis of heat transfer characteristics of fabrics in an open flame exposure. Textile Research Journal, 53(8), 475-482.

[2] Lee, Y. M., Barker, R. L. (1986). Effect of moisture on the thermal protective performance of heat-resistant fabrics. Journal of Fire Sciences, 4, 315-331.

[3] Sun, G., Yoo, H., Zhang, X., Pan, N. (2000). Radiant protective and transport properties of fabrics used by wildland firefighters. Textile Research Journal, 70(7), 567573.

[4] Lawson, L. K., Crown, E. M., Ackerman, M. Y., Dale, J. D. (2004). Moisture effects in heat transfer through clothing systems for wildland firefighters. International Journal of Occupational Safety and Ergonomics, 10(3), 227-238.

[5] Wang, Y. Y., Lu, Y. H., Li, J., Pan, J. H. (2012). Effects of air gap entrapped in Multilayer fabrics and moisture on thermal protective performance. Fibers and Polymers, 13(5), 647-652.

[6] Li, J., Li, Y., Li, X. H. (2012). Effect of relative humidity coupled with air gap on heat transfer of flame-resistant fabrics exposed to flash fires. Textile Research Journal, 82(12), 1235-1243.

[7] He, H. L., Yu, Z. C., Song, G. W. (2015). The effect of moisture and air gap on the thermal protective performance of fabric assemblies used by wildland firefighters. The Journal of The Textile Institute, 107(8), 1030-1036.

[8] Li, X. H., He, J., Li, J. (2014). Research on measuring stored thermal energy in protective clothing in thermal environment. China Personal Protective Equipment, (4), 45-47.

[9] Miao, Y., Li, J. (2016). Development and evaluation of firefighter's clothing capable of enhancing heat dissipation. Journal of Textile Research, 37(1), 111-115.

[10] Zhu, F. L., Zhang, W. Y.(2006). Evaluation of thermal performance of flame-resistant fabrics considering thermal wave influence in human skin model. Journal of Fibre Sciences, 24(6), 465-485.

[11] Su, Y., Li, J., Song, G. W. (2018). The effect of moisture content within multilayer protective clothing on protection from radiation and steam. International Journal of Occupational Safety and Ergonomics, 24(2), 190-199.

[12] He, J. Z., Li, J. (2016). Analyzing the transmitted and stored energy through multilayer protective fabric systems with various heat exposure time. Textile Research Journal, 86(3), 235-244.
[13] Rossi, R. M., Schmid, M., Camenzind, M. A. (2014). Thermal energy transfer through heat protective clothing during a flame engulfment test. Textile Research Journal, 84(13), 1451-1460.

[14] Zhai, L. N., Li, J. (2015). Prediction methods of skin burn for performance evaluation of thermal protective clothing. Burn, 41(7), 1385-1396.

[15] Torvi, D. A., Threlfall, T. G. (2006). Heat transfer model of flame resistant fabrics during cooling after exposure to fire. Fire Technology, 42(1), 27-48.

[16] Furmanski, P., Lapka, P. (2017). Evaluation of a temperature for the protective clothing-skin system based on the protective clothing-skin imitating materials results. International Journal of Heat and Mass Transfer, 114, 1331-1340.

[17] Wardiningsih, W., Troynikov, O. (2019). Energy absorption and thermal comfort of segmented pad for hip protective garment. International Journal of Clothing Science and Technology, 31(4), 564-577.

[18] Torvi, D. A., Hadjisophocleous, G. A. (1999). Research in protective clothing for firefighters: State of the art and future directions. Fire Technology, 35(2), 111-130.

[19] Torvi, D. A., Dale, J. D. (1998). Effects of variations in thermal properties on the performance of flame resistant fabrics for flash fires. Textile Research Journal, 68(11), 787-796.

[20] Song, G. W., Paskaluk, S., Sati, R., Crown, E. M., Dale, J. D., et al. (2011). Thermal protective performance of protective clothing used for low radiant heat protection. Textile Research Journal, 81(3), 311-323.

[21] Su, Y., He, J. Z., Li, J. (2016). Modeling the transmitted and stored energy in multilayer protective clothing under low-level radiant exposure. Applied Thermal Engineering, 93, 1295-1303.

[22] Li, J., Lu, Y. H., Li, X. H. (2012). Effect of relative humidity coupled with air gap on heat transfer of flame-resistant fabrics exposed to flash fires. Textile Research Journal, 82(12), 1235-1243.

[23] Zhang, M. Y., Miao, Y., Li, J. (2016). Influence factors and evaluation methods of stored thermal energy in firefighters protective clothing. Journal of Textile Research, 37(6), 171-176.

[24] He, H. L., Yu., Z. C. (2018). Effect of air gap entrapped in firefighter protective clothing on thermal resistance and evaporative resistance. Autex Research Journal, 18(1), 28-34.

[25] Barker, R. L., Deaton, A. S., Ross, K. A. (2010). Heat transmission and thermal energy storage in firefighter turnout suit materials. Fire Technology, 47(3), 549-563. 